\title{
Mathematical Modeling and Optimization of Functionally Graded Structures
}

\author{
Abdelouahed Tounsi, ${ }^{1}$ El Abbes Adda Bedia, ${ }^{1}$ S. R. Mahmoud, ${ }^{2,3}$ and Sofiane Amziane ${ }^{4}$ \\ ${ }^{1}$ Laboratoire des Matériaux et Hydrologie, Département de Génie Civil, Faculté de Technologie, Université de Sidi Bel Abbes, Algeria \\ ${ }^{2}$ Department of Mathematics, Faculty of Science, King Abdulaziz University, Saudi Arabia \\ ${ }^{3}$ Mathematics Department, Faculty of Science, University of Sohag, Egypt \\ ${ }^{4}$ Clermont Université, Polytech'Clermont-Ferrand, EA 3867, LaMI, BP 10448, 63000 Clermont-Ferrand, France
}

Correspondence should be addressed to Abdelouahed Tounsi; tou_abdel@yahoo.com

Received 26 September 2013; Accepted 26 September 2013

Copyright ( 2013 Abdelouahed Tounsi et al. This is an open access article distributed under the Creative Commons Attribution License, which permits unrestricted use, distribution, and reproduction in any medium, provided the original work is properly cited.

Functionally graded structures such as beams, plates, and shells are those in which the volume fractions of two or more materials are varied continuously as a function of position along certain direction(s) of the structure to achieve a required function. Due to the dramatic increase in the use of functionally graded materials (FGMs) in a variety of engineering structures (e.g., mechanics, aerospace, automotive, nuclear, civil engineering, and medical prosthetics), as typical and principal mathematical issues, modeling and optimization of functionally graded structures have attracted the attention of many scientists in recent years for predicting the mechanical behavior of such structures [1-9].

This special issue collects selected papers on modeling aspects and the analysis of structures embedding functionally graded materials (FGMs).

S. Topal and S. Dag presented in their paper two different $J_{k}$-integral-based computational techniques, which can be used to conduct fracture mechanics analysis of orthotropic functionally graded materials subjected to hygrothermal stresses. The methods presented in this paper are shown to be effective ways of taking into account hygrothermal effects and evaluating fracture mechanics parameters and thus can be used to solve fracture and fatigue problems involving complex geometric configurations and loading conditions.

In the paper by S. R. Mahmoud et al., the effect of nonhomogeneity and rotation on the free vibrations for elastodynamic problem of orthotropic hollow sphere is discussed. Comparisons are made with the result in the presence and absence of nonhomogeneous and rotation in cases of orthotropic hollow sphere. An analytic solution method, without integral transformation, is developed in the paper by S. Y. Lee and C. C. Huang to find the exact solutions for transient heat conduction in functionally graded circular hollow cylinders with time-dependent boundary conditions. Limiting studies and numerical analyses are given to illustrate the efficiency and the accuracy of the analysis. Y. Yilmaz et al. introduced a localized differential quadrature method (LDQM) for buckling analysis of axially functionally graded nonuniform columns with elastic restraints. To the best of these authors' knowledge, in the open literature, LDQM has not been applied before to solutions of generalized eigenvalue problems governed by fourth-order variable coefficient differential equations. Comparison of the results obtained by Y. Yilmaz et al. shows the potential of the LDQM for solving such generalized eigenvalue problems governed by fourth-order variable coefficient differential equations with high accuracy and less computational effort.

Nonlocal elasticity model for bending analysis of sigmoid functionally graded materials (S-FGMs) nanoscale plates is presented in the paper by W. Y. Jung and S. C. Han using a first-order shear deformation theory and Hamilton's principle. The material properties of S-FGM nanoscale plate are assumed to vary according to sigmoid function (two power law distributions) of the volume fraction of the constituents. The effects of nonlocal parameters, power law index, aspect ratio, elastic modulus ratio, side-to-thickness ratio, and loading type on bending and vibration response are investigated in detail. The work presented in the paper 
by W. Y. Jung and S. C. Han can be helpful while designing nanoelectromechanical system and microelectromechanical system devices using the S-FGM nanoscale plates. In the paper of F. Tornabene and A. Ceruti, the generalized differential quadrature method has been presented as a means, to investigate the static and dynamic analysis of functionally graded and laminated composite doubly curved shells and panels. The mechanical models presented by F. Tornabene and A. Ceruti, is based on the so-called first-order shear deformation theory (FSDT). Three different optimization schemes and methodologies are implemented. The particle swarm optimization, Monte Carlo, and genetic algorithm approaches have been applied to define the optimum volume fraction profile for optimizing the first natural frequency and the maximum static deflection of the considered shell structure.

In the paper presented by A. E. Alshorbagy et al., the boundary value problem of the uncoupled thermoelastic behavior of functionally graded plate is formulated and solved. First, the temperature distribution is predicted to be used in the thermoelastic analysis of functionally graded plate. Then, a finite element model based on the firstorder shear deformation plate (FSDT) theory is proposed, accounting for the exact neutral plane position, for modeling the functionally graded plates. A comparative study is performed to illustrate the effect of considering the neutral plane position.

The paper presented by S. Kim et al. deals with the thermoelastic characteristics of circular disk TBC specimens with and without a functionally graded layer between the top and bond coats. Two partial differential equations are derived based on thermoelastic theory, and the thermoelastic characteristics, such as temperature distribution profiles, displacement, and stresses, are determined through mathematical approaches. Because of the complexity of the governing equations, a finite volume approach is adopted to analyze the thermoelastic characteristics.

The papers published in this special issue only discuss some of the most significant topics about the mathematical modeling and optimization of functionally graded structures. However, the included papers present significant contributions and promising methods.

\section{Acknowledgments}

We, the guest editors, would like to take this opportunity to thank all the authors for their valuable contributions as well as the anonymous reviewers for their comments and suggestions. The authors acknowledge the Deanship of Scientific Research (DSR), King Abdulaziz University, Jeddah, for the research grant and the technical and financial support. The support for this special issue by University of Sidi Bel Abbes (Algeria), and Clermont University, Institut Pascal, Clermont-Ferrand (France), is gratefully acknowledged.

Abdelouahed Tounsi El Abbes Adda Bedia S. R. Mahmoud Sofiane Amziane

\section{References}

[1] A. Bessaim, M. S. A. Houari, A. Tounsi, S. R. Mahmoud, and E. A. Adda Bedia, "A new higher-order shear and normal deformation theory for the static and free vibration analysis of sandwich plates with functionally graded isotropic face sheets," Journal of Sandwich Structures and Materials, vol. 15, pp. 671703, 2013.

[2] H. Hebali, A. Tounsi, M. S. A. Houari, A. Bessaim, and E. A. Adda Bedia, "A new quasi-3D hyperbolic shear deformation theory for the static and free vibration analysis of functionally graded plates," Journal of Engineering Mechanics (ASCE). In press.

[3] A. Tounsi, M. S. A. Houari, S. Benyoucef, and E. A. Adda Bedia, "A refined trigonometric shear deformation theory for thermoelastic bending of functionally graded sandwich plates," Aerospace Science and Technology, vol. 24, pp. 209-220, 2011.

[4] H. Saidi, M. S. A. Houari, A. Tounsi, and E. A. Adda Bedia, "Thermo-mechanical bending response with stretching effect of functionally graded sandwich plates using a novel shear deformation theory," Steel and Composite Structures, vol. 15, pp. 221-245, 2013.

[5] K. Bakhti, A. Kaci, A. A. Bousahla, M. S. A. Houari, A. Tounsi, and E. A. Adda Bedia, "Large deformation analysis for functionally graded carbon nanotube-reinforced composite plates using an efficient and simple refined theory," Steel and Composite Structures, vol. 14, no. 4, pp. 335-347, 2013.

[6] N. Ziane, S. A. Meftah, H. A. Belhadj, A. Tounsi, and E. A. Adda Bedia, "Free vibration analysis of thin and thick-walled FGM box beams," International Journal of Mechanical Sciences, vol. 66, pp. 273-282, 2013.

[7] L. Ould Larbi, A. Kaci, M. S. A. Houari, and A. Tounsi, "An efficient shear deformation beam theory based on neutral surface position for bending and free vibration of functionally graded beams," Mechanics Based Design of Structures and Machines, vol. 41, pp. 421-433, 2013.

[8] M. S. A. Houari, A. Tounsi, and O. Anwar Bég, "Thermoelastic bending analysis of functionally graded sandwich plates using a new higher order shear and normal deformation theory," International Journal of Mechanical Sciences, vol. 76, pp. 102-111, 2013.

[9] A. Fekrar, N. El Meiche, A. Bessaim, A. Tounsi, and E. A. Adda Bedia, "Buckling analysis of functionally graded hybrid composite plates using a new four variable refined plate theory," Steel and Composite Structures, vol. 13, no. 1, pp. 91-107, 2012. 


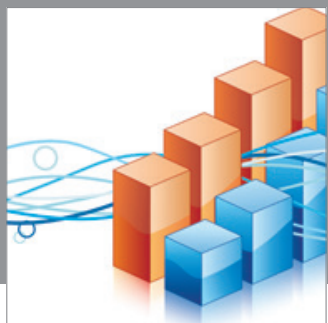

Advances in

Operations Research

mansans

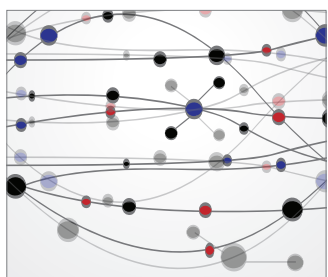

The Scientific World Journal
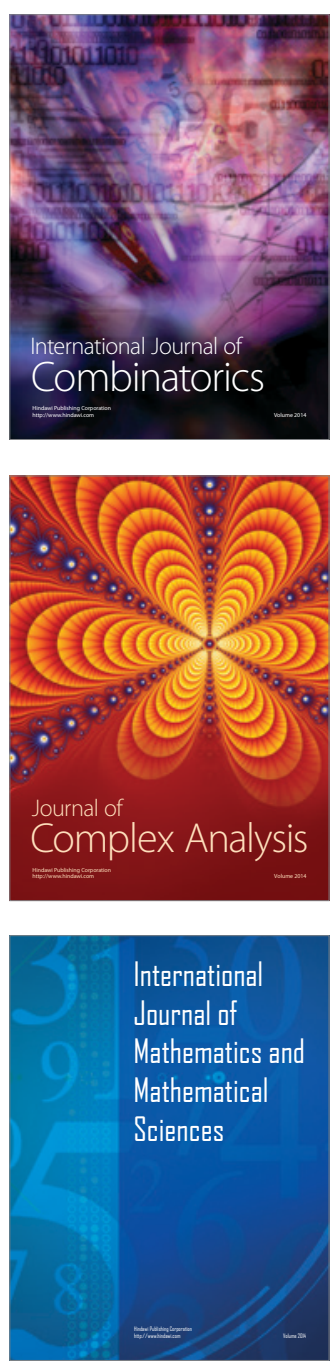
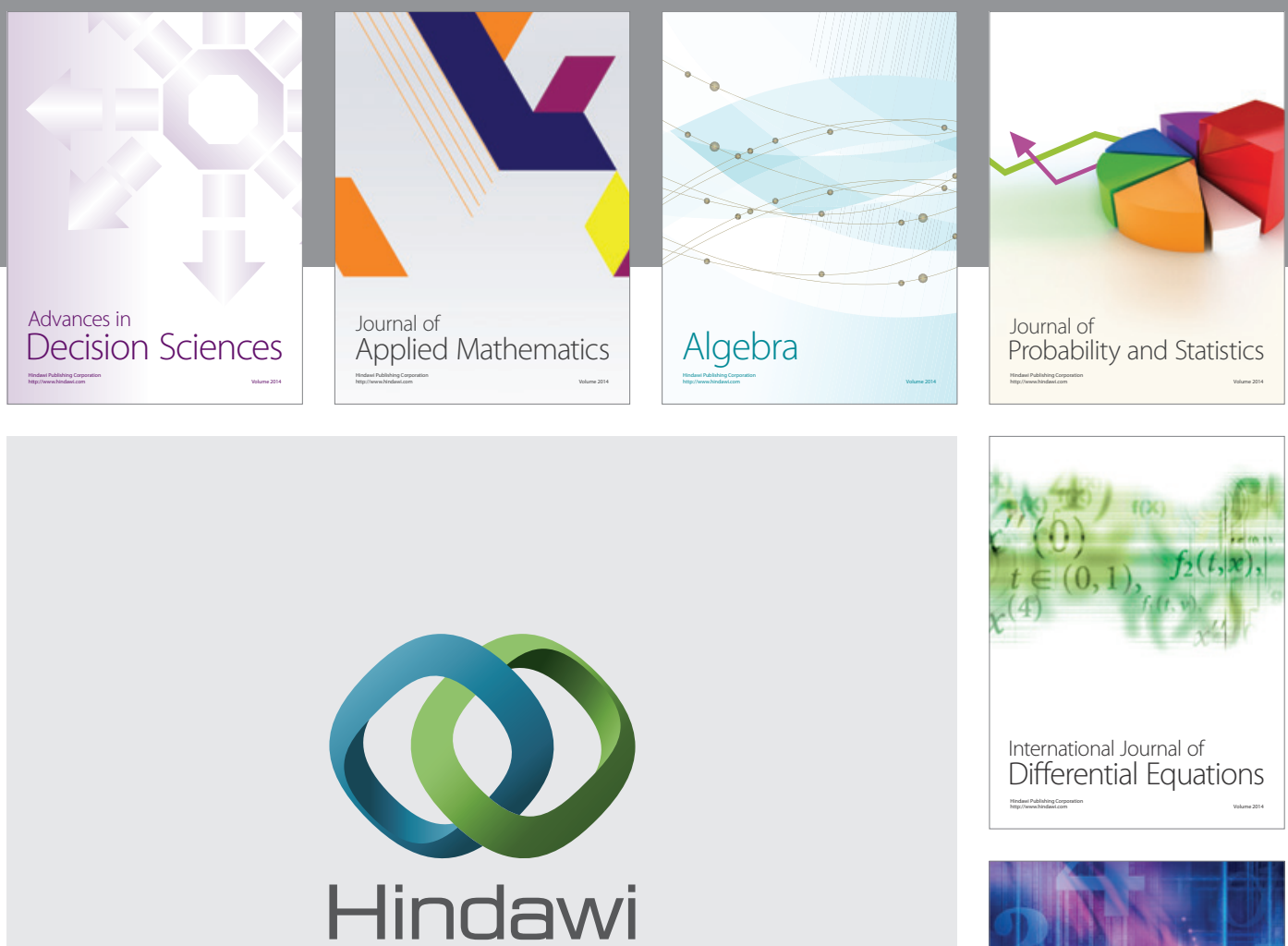

Submit your manuscripts at http://www.hindawi.com
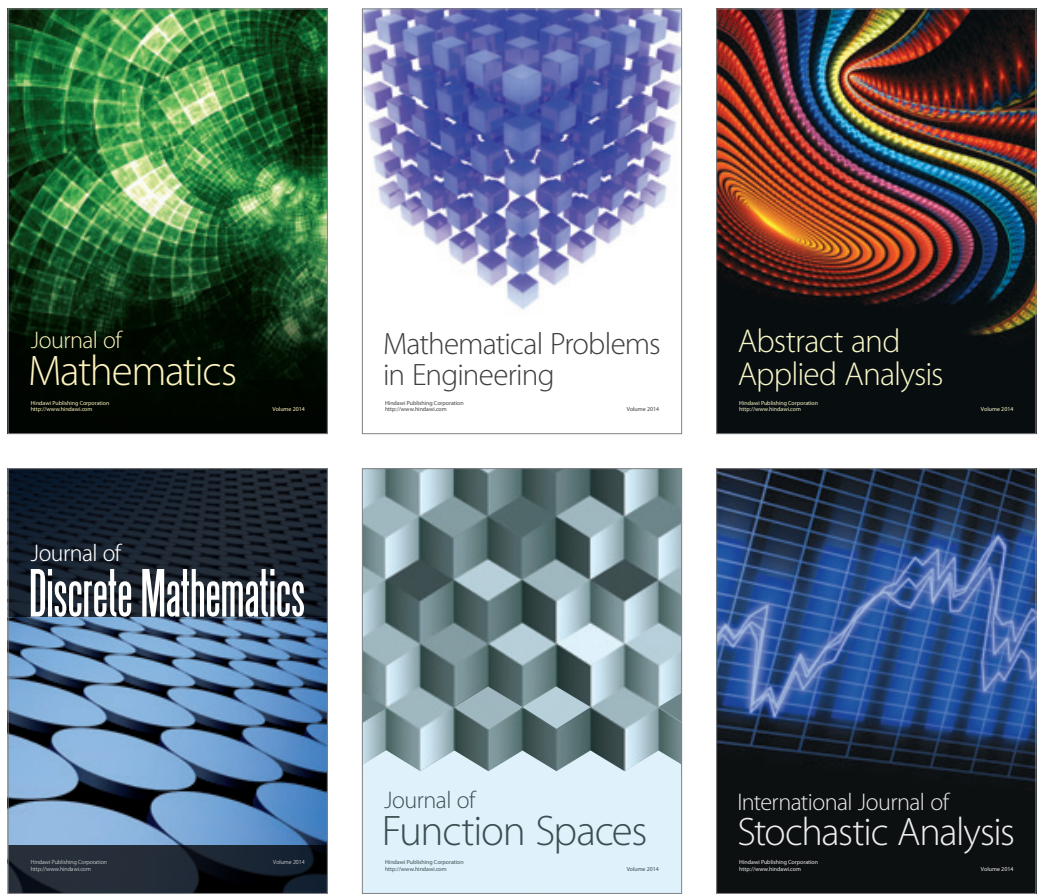

Journal of

Function Spaces

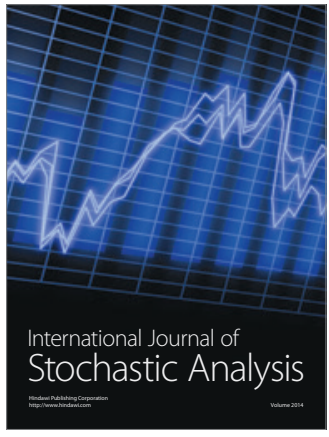

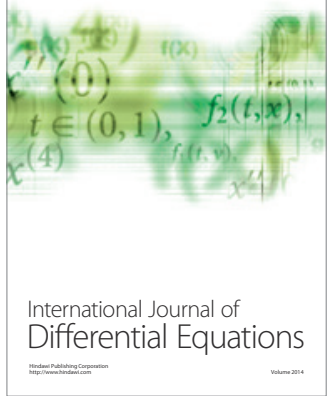
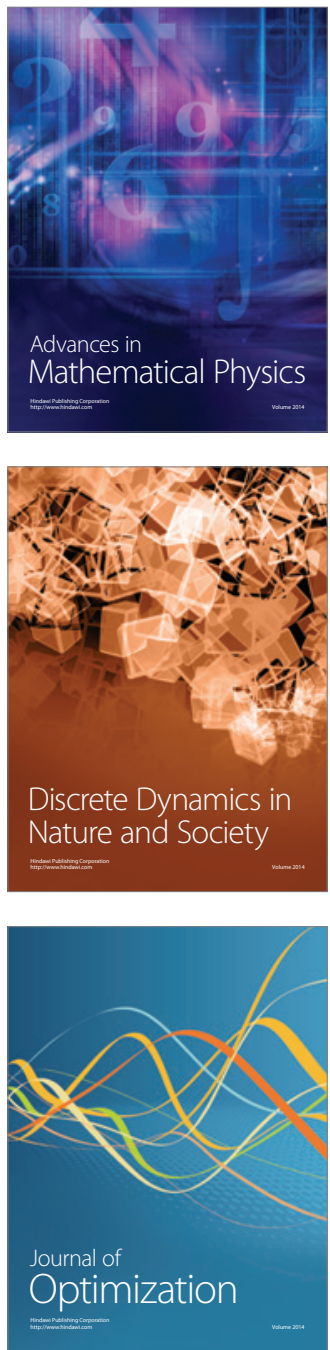